\title{
Comparative Evaluation of Ultraviolet, Microwave and Antimicrobial Sterilization Techniques for Toothbrush Decontamination
}

\author{
Gazalla Altaf' Bhavika Sharma Aaquib Hussain' Bhavna Gupta' Saraf Neha Sheoran ${ }^{1}$
}

'Department of Pedodontics and Preventive Dentistry, Sudha Rustagi College of Dental Sciences and Research, Faridabad, Haryana, India ${ }^{2}$ Department of Oral and Maxillofacial Surgery, Sudha Rustagi College of Dental Sciences and Research, Faridabad, Haryana, India

\author{
Address for correspondence: Gazalla Altaf, Department of \\ Pedodontics and Preventive Dentistry, Sudha Rustagi College of \\ Dental Sciences and Research, Sector 89, Kheri More, Faridabad, \\ Haryana, India \\ E-mail: gazalaaltaf91@gmail.com
}

\begin{abstract}
Objective: This study aimed to study the antimicrobial efficacy of sanitization of toothbrushes using: Ultraviolet (UV) light sanitizer, domestic microwave oven (MO), $0.2 \%$ chlorhexidine gluconate $(\mathrm{CHX})$ and to estimate the microbial contamination of toothbrushes when stored: inside the bathroom and outside the bathroom.

Materials and Methods: The toothbrushes were divided into two groups: Group I $(n=45)$ stored inside the bathroom and Group II ( $n=45)$ stored outside the bathroom. Group I and Group II was further sub divided into three groups and then subjected to different sanitization methods: Ultraviolet light sanitizer, domestic microwave oven, and $0.2 \%$ chlorhexidine gluconate.

Results: Contamination is found to be less in the brushes kept outside the bathroom as compared to brushes kept inside the bathroom and Most effective method for sanitization of toothbrushes is microwave irradiation followed by UV rays and then chlorhexidine gluconate solution.
\end{abstract}

Conclusion: Toothbrushes should always be stored outside the bathroom so that they are out of the aerosol range and proper storage \& disinfection of the toothbrush is as important as brushing your teeth for a healthy and germ-free life.

Keywords: Antimicrobial solution, disinfection, microwave, sterilization, toothbrush

\section{Introduction}

The oral cavity is considered to be free of microorganisms at birth, because the fetus develops in sterile conditions.[1-3] During birth and immediately thereafter the neonate contacts the microbial inhabitants of the immediate environment and there is a great increase in the number of detectable microorganisms in the oral cavity in about 8 hours after the birth. There is an unlimited diversity of microorganisms in the oral cavity during the first day of life, such as Streptococcus, Neisseria, Staphylococcus, Candida, Lactobacillus, Veillonella and coliforms.[1] However, mutans streptococci, is present only after the eruption of first tooth in the oral cavity because it establishes on hard surfaces. $[4,5]$ According to the literature, the main source of mutans streptococci is the mother,[6,7] or other family members.[8] Day-care centers present a potential risk

How to cite this article: Altaf G, Sharma B, Hussain A, Gupta B, Sheoran SN. Comparative Evaluation of Ultraviolet, Microwave and Antimicrobial Sterilization Techniques for Toothbrush Decontamination. J Pediatr Dent 2021;7(1):00-00 
for infection among children. Spread can occur through direct (saliva) or indirect communication. [7] Spread through Indirect means can happen through fomites, such as spoons,[9] cups, toys or soiled toothbrushes. $[7,10]$

Sumerians practiced oral hygiene in early $3000 \mathrm{BC}$; Chinese were the earliest people to use chewable sticks which were made up of roots or branches of the plant for cleaning the teeth. Bristled toothbrush emerged about year $1600 \mathrm{AD}$. For keeping the oral hygiene good toothbrush is one of the most commonly used method. Today, the market is saturated with various brand names of toothbrushes, oral rinses and toothpastes each alleging superiority over the other. But little do we pay attention that despite cleaning the teeth, the brush could be possibly contaminating them.[11]

Toothbrushes could serve as a means of transmission of pathogenic microorganisms via gingival lesions in patients who are supposed to undergo organ transplantation or whose immunity is depressed.[12] Under normal storage conditions, toothbrushes can be responsible for spread or reinfection of diseases such as herpes or periodontopathogenic microbes and coliforms from bathroom environment. Glass found that certain viruses like herpes simplex virus - 1 can remain viable for at least $48 \mathrm{~h}$ on a dried toothbrush and for 1 day in humid conditions.[12].

To prevent or minimize the chances of infection or re-infection numerous ways are available like Microwave, ultraviolet rays and antimicrobial solutions (Chemicals: chlorhexidine, cetylpyridinium chloride, Listerine and several dentifrices; natural agents: garlic and tea tree oil extracts) $[13,14]$ However, no systematic review is available which can be an effective intervention for sanitization. Thus, the present investigation was designed to study the antimicrobial efficacy of sanitization of toothbrushes using: ultraviolet light sanitizer, domestic microwave oven, $0.2 \%$ chlorhexidine gluconate and to estimate the microbial contamination of toothbrushes when stored: Inside the bathroom and Outside the bathroom.

\section{Materials and Methods}

\section{Sample size}

This study has followed the CRIS guidelines for in-vitro studies as discussed in the 2014 concept note.

A prior sample size was calculated using $G$ power software (version 3.0).

The toothbrushes were obtained from subjects aged 18-21 years studying in a private dental college. The study subjects, the microbiologist, and the statistician were blinded.

\section{Participants}

Participants were fully explained about the study verbally and through patient information sheet and written informed consent was obtained.

\section{Ethical considerations}

Institutional ethical clearance was obtained prior carrying out the study. (Letter No SRCDSR/ACAD/2019/9910)

\section{Inclusion criteria}

- Subjects in good general health

- Having DMFT score $=0$

- Brushing=twice a day \& maintain their normal routine.

\section{Exclusion criteria}

- Clinical evidence - gross caries or periodontal disease

- Any systemic disease

- Using any antibiotics, mouthwashes, chewing gums, tobacco

- Any dental treatment, including orthodontic treatment or with extensive intraoral prosthesis

\section{Data collection}

The toothbrushes were divided into two groups: Group I $(n=45)$ stored inside the bathroom and Group II $(n=45)$ stored outside the bathroom. Group I and Group II was further sub divided into three groups and then subjected to different sanitization methods: ultraviolet light sanitizer, domestic microwave oven and, $0.2 \%$ chlorhexidine gluconate.

\section{Procedure}

Step 1: Before distribution, new toothbrushes were checked for the presence of any contamination by immersing the Brush Heads in liquid nutrient broth solution for 24 hours (Fig. 1). After 24 hrs it was seen that solution was clear and transparent, which means no turbidity was found (Fig. 2). For confirmation, the liquid broth was transferred on the surface of solid nutrient agar. No bacterial growth was observed, which Indicates that new toothbrushes were free of any contamination (Fig. 3).

Step 2: Toothbrushes were distributed to subjects in both the groups with reinforcement of instructions (Fig. 4). After a week toothbrush were collected from the participants and subjected to microbial analysis. 

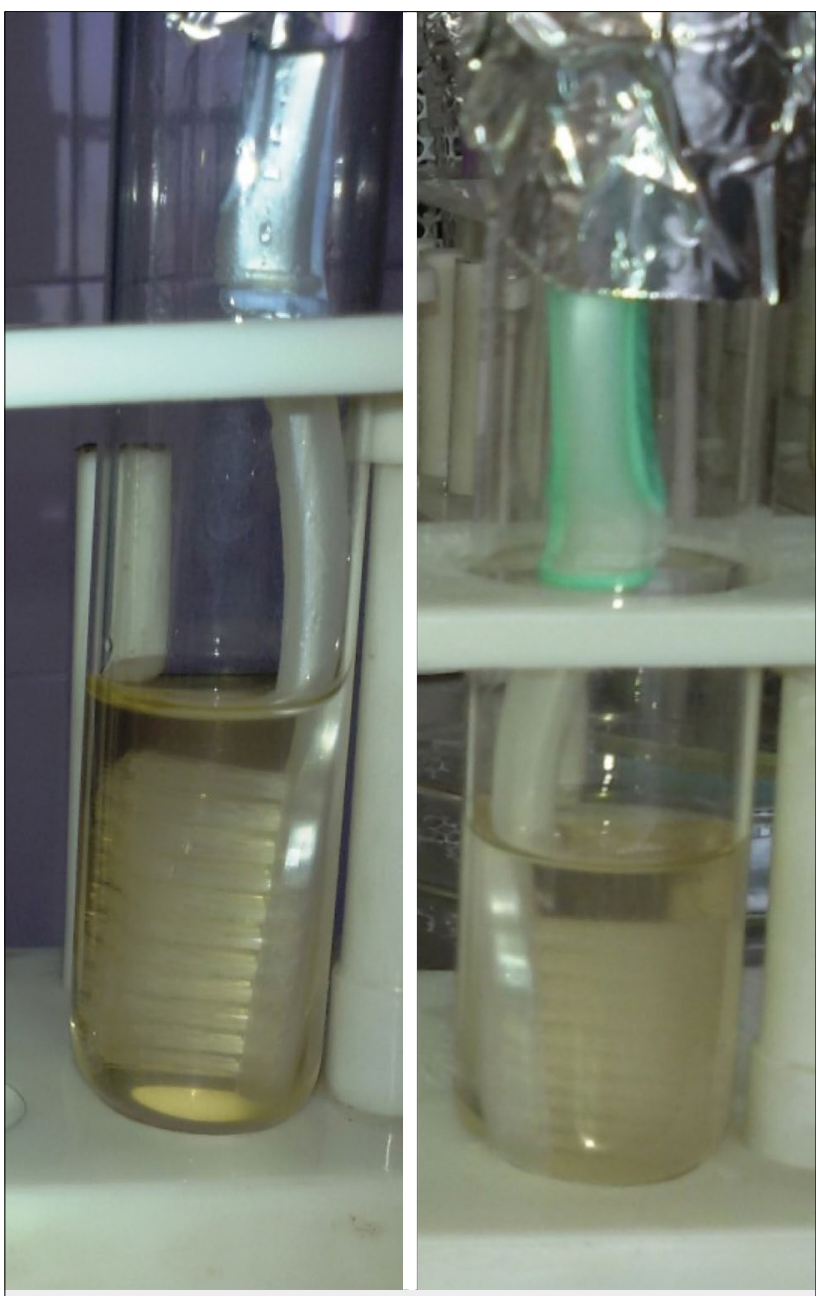

Figure 1. Unused brush heads immersed in liquid nutrient broth solution

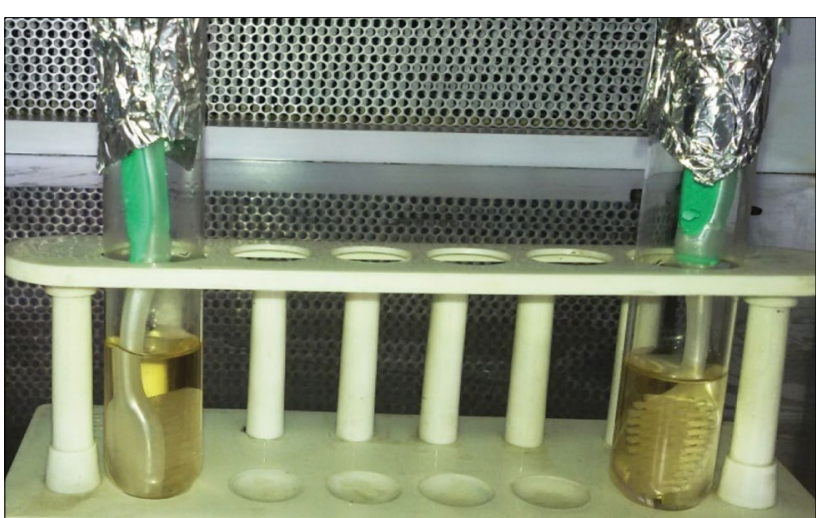

Figure 2. Clear and transparent solution indicating no turbidity

Step 3: All the toothbrushes were immersed in liquid nutrient broth (Fig. 5) and kept in the incubator for 24 hours (Fig. 6). Turbidity was observed in nutrient broth indicating contamination of used toothbrushes (Fig. 7). For confirmation nutrient broth was transferred on the surface of the solid nutrient agar and kept

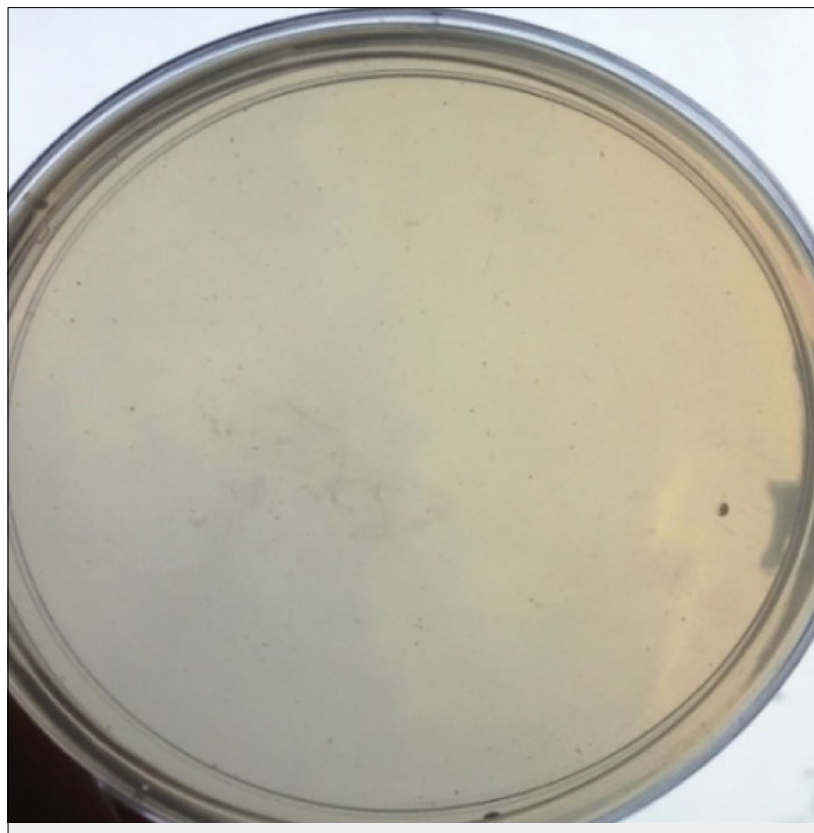

Figure 3. No bacterial growth was observed on solid nutrient agar

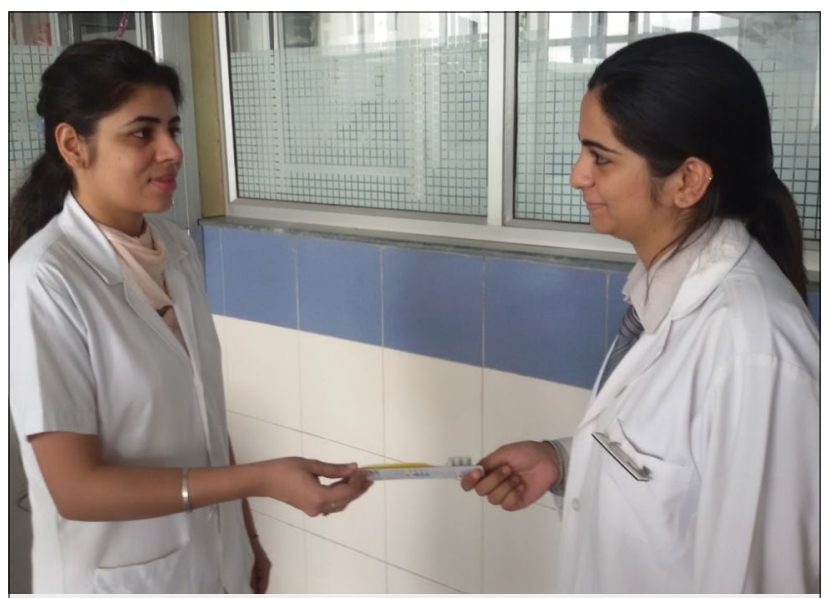

Figure 4. Distribution of toothbrushes

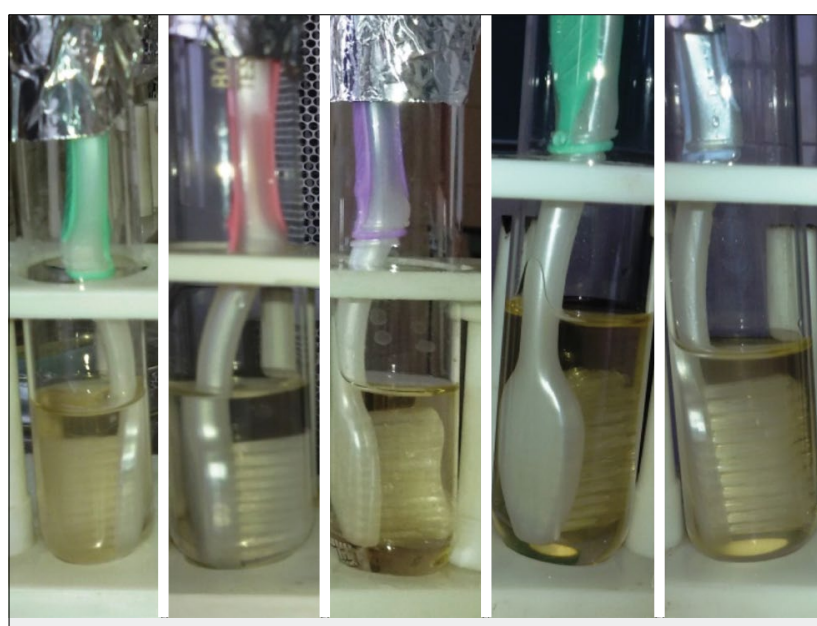

Figure 5. Toothbrushes immersed in liquid nutrient broth 


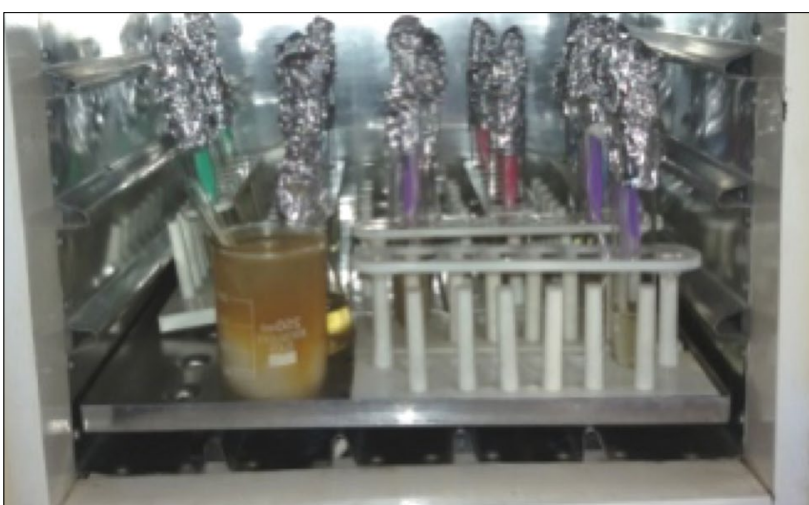

Figure 6. Toothbrushes kept in incubator

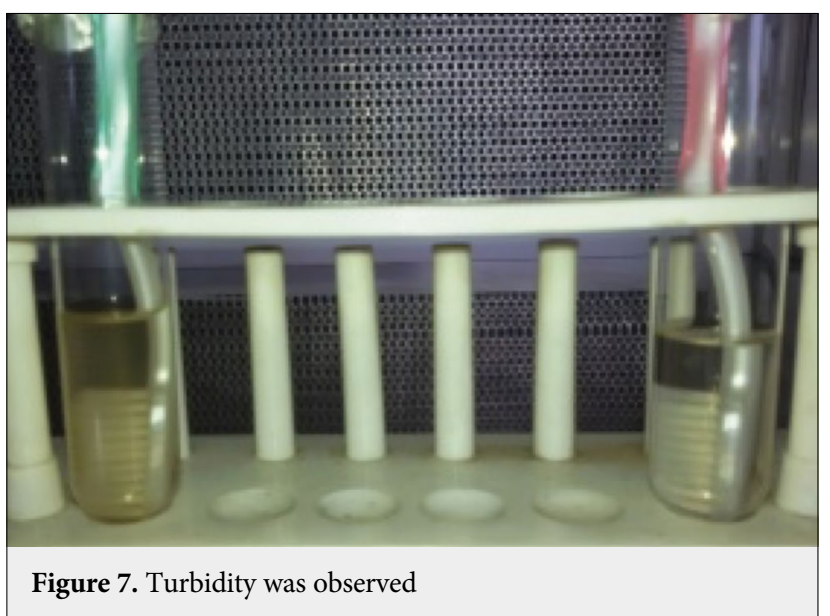

in incubator for 24 hours (Fig. 8). After 24 hours, bacterial growth was appreciated and the CFU's were counted (Fig. 9).

Step 4: After counting the CFU's, the brushes were properly washed with distilled water, dried and then subjected to three different sterilization procedures.

UV toothbrush sanitizer (PureOne, Pure One Labs Pvt. Ltd. Jammu Tawi, India); Used as per manufacturer's instructions i.e the UV lamp automatically turns off

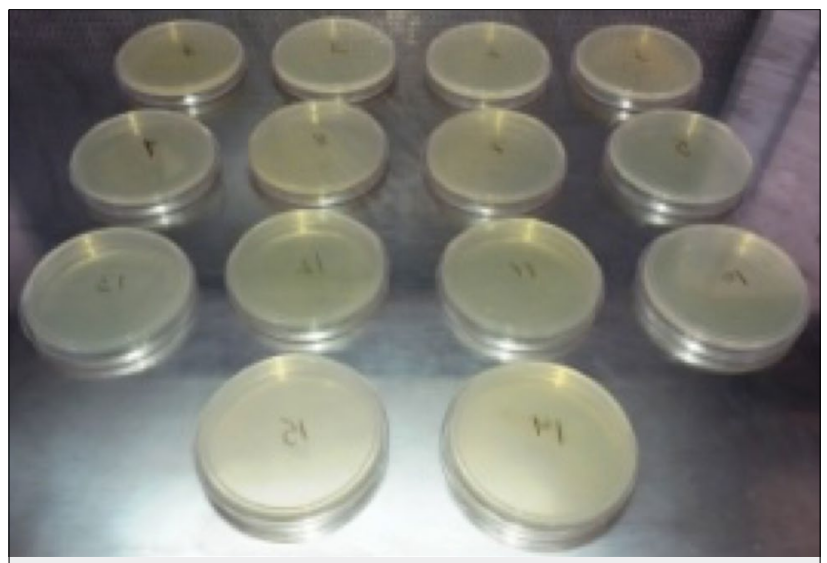

Figure 8. Nutrient broth was transferred on the surface of the solid nutrient agar and kept in incubator

after 10 - 20 minutes indicating that the bactericidal process is completed (Fig. 10).

Microwave Oven (2450 MHz, LG Home appliances) The brush was subjected to its maximum setting for 5 minutes (Fig. 11).

Chlorhexidine gluconate solution (0.2\%) - Brush was immersed for 12 hours in the mouthwash solution without its dilution (Fig. 12).

Step 4: After sterilization, CFU's were obtained and counted using the same procedure as was done previously (Fig. 13).

\section{Statistical analysis}

The data was collected and entered in the excel sheet using Microsoft Excel Software and was transferred to statistical package for social sciences (SPSS) version 21 (IBM corp. Statistical Package for Social Sciences for Windows, Armonk, NY, USA) for analysis. It was subjected to descriptive statistics for calculation of mean, standard deviation, absolute and relative frequencies. Categorical variables were compared using Chi square test. The level of significance was set at $0.05 \%$.
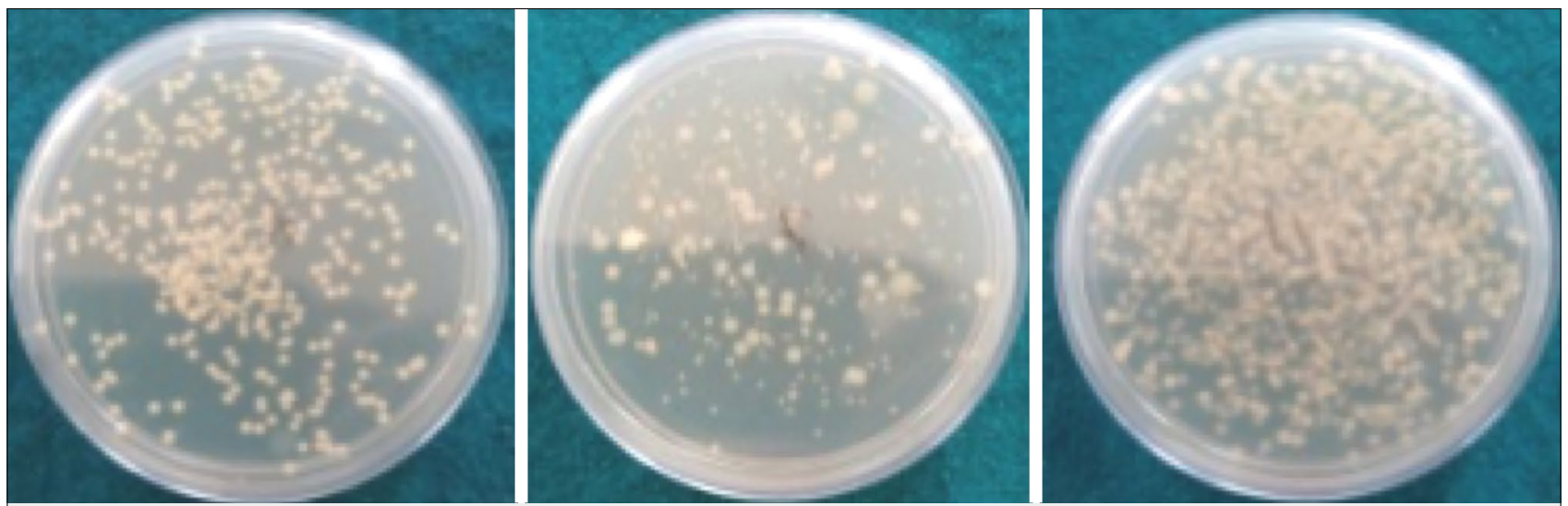

Figure 9. Bacterial growth was appreciated and the CFU's were counted 


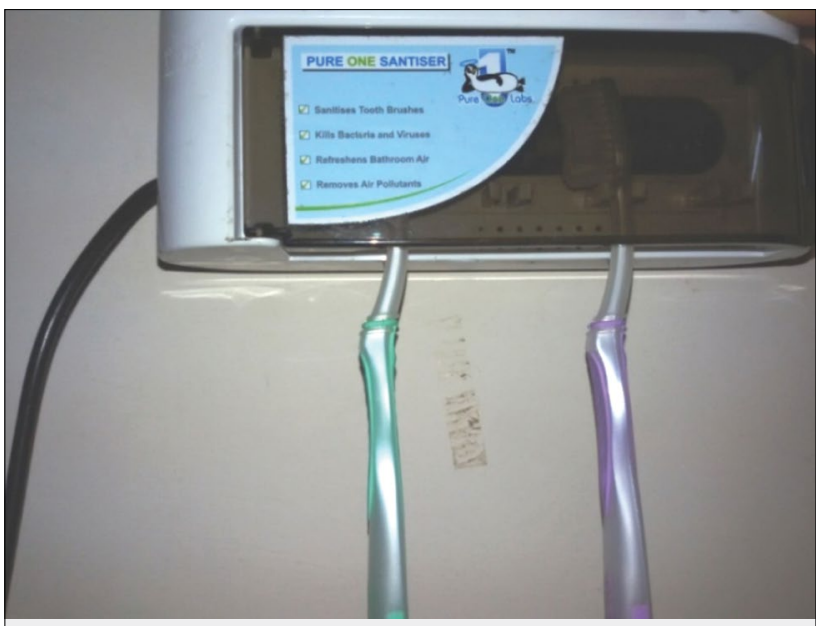

Figure 10. Toothbrushes kept in UV toothbrush sanitizer

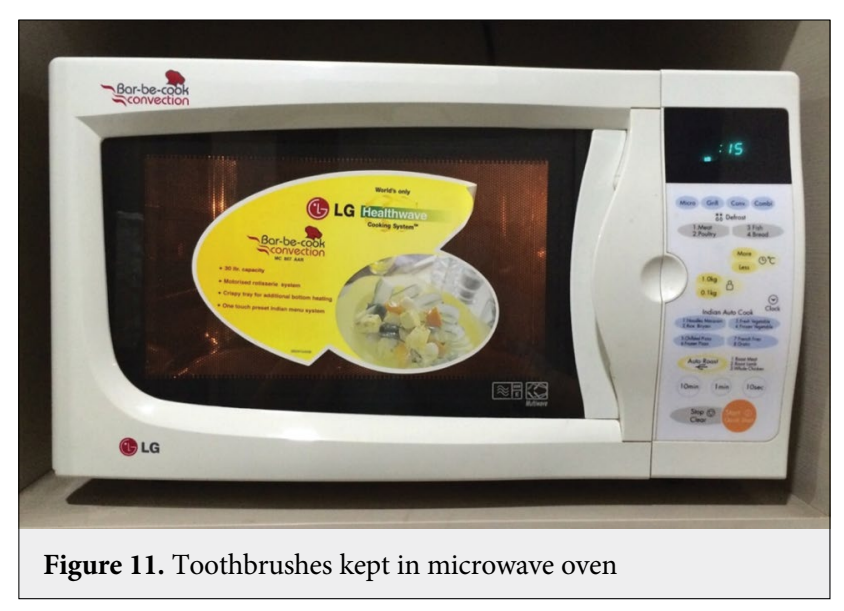

\section{Results}

Unused toothbrushes when cultured resulted in negative culture which means that new toothbrushes were free of any contamination (Fig. 3).

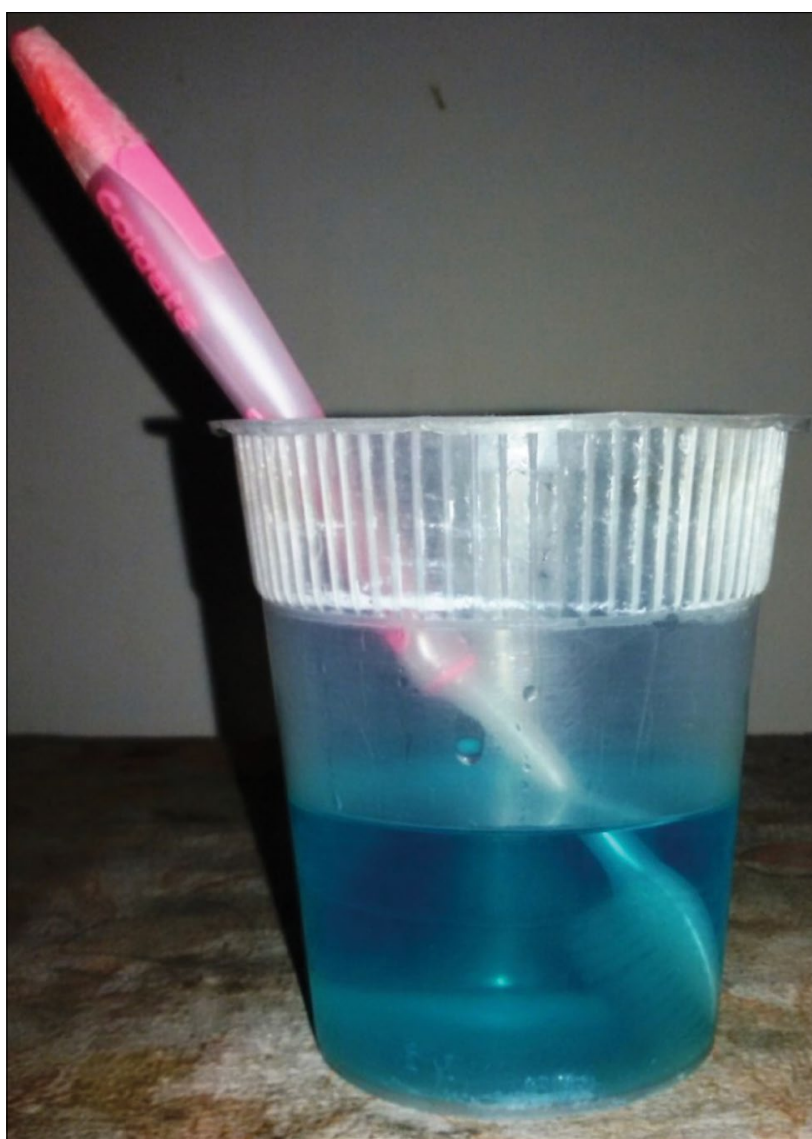

Figure 12. Toothbrushes immersed in chlorhexidine gluconate solution (CHX) (0.2\%)

Microwave irradiation is an effective means of sterilization compared to UV radiation followed by chlorhexidine gluconate solution (0.2\%) (Table 1 and 2 ). Inside the bathroom, significant reduction was seen in CFU when treated with UV, microwave radiation or CHX. Maximum reduction in CFU postintervention were seen in microwave group followed by UV and CHX

Table 1. Contamination load in terms of CFU inside the bathroom

\begin{tabular}{|c|c|c|c|c|c|c|c|}
\hline & Mean & $\mathbf{n}$ & Std. Deviation & Std. Error Mean & Mean difference & SD & $P$ value \\
\hline \multicolumn{8}{|l|}{ UV } \\
\hline Pre & 496733.333 & 15 & 845731.5909 & 218366.9578 & \multirow{2}{*}{496731.4000} & \multirow{2}{*}{845730.5713} & \multirow{2}{*}{0.039} \\
\hline Post & 1.933 & 15 & 1.5796 & 0.4079 & & & \\
\hline \multicolumn{8}{|l|}{ MO } \\
\hline Pre & 443060.000 & 15 & 616811.6439 & 159260.0816 & \multirow{2}{*}{443058.7333} & \multirow{2}{*}{616812.3729} & \multirow{2}{*}{0.015} \\
\hline Post & 1.267 & 15 & 2.0517 & 0.5297 & & & \\
\hline \multicolumn{8}{|l|}{ CHX } \\
\hline Pre & 164213.333 & 15 & 74319.0984 & 19189.1087 & \multirow{2}{*}{164207.0000} & \multirow{2}{*}{74317.8466} & \multirow{2}{*}{0.0001} \\
\hline Post & 6.333 & 15 & 5.0521 & 1.3044 & & & \\
\hline \multicolumn{8}{|c|}{$P$ value 0.001} \\
\hline Microwa & $\mathrm{V}>\mathrm{CHX}$ & & & & & & \\
\hline
\end{tabular}


Table 2. Contamination load in terms of CFU outside the bathroom

\begin{tabular}{|c|c|c|c|c|c|c|c|}
\hline & Mean & $\mathbf{n}$ & Std. Deviation & Std. Error Mean & Mean difference & SD & P value \\
\hline UV & & & & & & \\
\hline Pre & 470606.667 & 15 & 757353.5865 & 195547.8552 & 470602.0667 & 757352.0276 & 0.030 \\
\hline Post & 4.600 & 15 & 3.7947 & 0.9798 & & & \\
\hline Pre & 99506.667 & 15 & 55809.9641 & 14410.0708 & 99506.1333 & 55809.3504 & 0.0001 \\
\hline Post & 0.533 & 15 & .8338 & 0.2153 & & & \\
\hline CHX & & & & & & & \\
\hline Pre & 48766.667 & 15 & 25346.9262 & 6544.5482 & 48763.8000 & 25344.2222 & 0.0001 \\
\hline \multicolumn{2}{|c|}{ Post } & 2.867 & 15 & 4.7789 & 1.2339 & & \\
\hline P value $<0.001$ & & & & \\
\hline Microwave $>$ UV $>$ CHX & & & & & \\
\hline
\end{tabular}

UV: Ultraviolet, MO: Microwave oven, CHX: Chlorhexidine gluconate, SD: Standard deviation

Table 3. Comparison of difference in CFU from pre to post

\begin{tabular}{|l|c|c|c|c|c|}
\hline & Group & n & Mean & Std. Deviation & Std. Error Mean \\
\hline Difference in CFU from pre to post & Inside & 45 & 367999.0444 & 610019.17694 & 90936.28981 \\
\hline & Outside & 45 & 206290.6667 & 468894.25036 & 69898.62787 \\
\hline P value & 0.162 NS & & & & \\
\hline
\end{tabular}
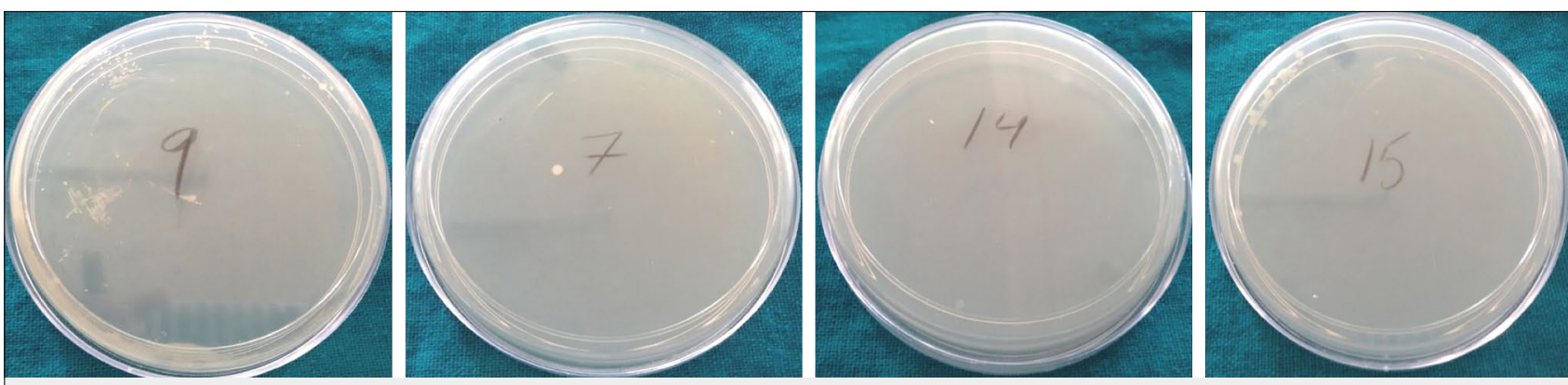

Figure 13. CFU's were counted

(Table 1). Outside the bathroom, significant reduction were seen in CFU when treated with UV, microwave radiation or CHX. Maximum reduction in CFU postintervention were seen in Microwave group followed by UV and CHX (Table 2).

Contamination is found to be less in the brushes kept outside the bathroom as compared to toothbrushes kept inside the bathroom (Table 3). Though microbial contamination was found to be lesser when tooth brushes were kept outside the bathroom but it failed to reach the level of statistical significance as $\mathrm{p}>0.05$.

\section{Discussion}

As practising clinicians, utmost care must be taken for daily sterilization and disinfection procedures of our instruments and workplace. However, we usually show negligence to disinfect the one that is used every day to clean our mouth, that is, toothbrush. Accumulation of microorganisms on toothbrushes has received little attention.[15] The reason might be that toothbrushes are considered only as a device to prevent plaque formation and hence caries by removing debris and food particles between the teeth. There are several sources of microbes, which were seen on toothbrushes and these microorganisms on a toothbrush may be a mirror image of microorganisms in the oral cavity of the user.[16] Mutans streptococci, the main etiological agent of the dental caries, can also be transferred by toothbrushes, intra- or inter-individual, thereby increasing the occurrence of dental caries, especially in children.[17] For the endurance or existence of bacteria the conditions in 
which the toothbrushes are stored are considered to be an important factor. Dayoub et al[18] and Meier et al[19] reported that the number of microbes on the toothbrushes kept in aerated conditions was lower than in toothbrushes stored in plastic bags. Several authors have reported that microbial contamination can be lowered down by washing toothbrushes after use, and drying in aerated conditions.[17,20-22] Caudry et al[23] reported that a humid surroundings increases microbial growth and cross infection. Therefore, bacterial growth tends to increase in the toothbrushes as the time period between one toothbrushing and another increases, when stored in a wet/moisture environment.[17]

To minimize the number of microbes on the bristles several investigators have suggested the need for toothbrush disinfection, using approaches such as UV-radiation, microwave oven, boiling water[24] and chemical agents such as Listerine Plax,[23] and Cepacol.[19,23] Caudry et al[23] suggested that immersing the toothbrush in Listerine, for $20 \mathrm{~min}$ is an effective method of disinfection. Meier et al [19] used cetylpyridinium chloride spray over the bristles and $100 \%$ reduction of S. epidermidis and $94 \%$ for Candida albicans was seen.

The present investigation was designed to study the antimicrobial efficacy of of sanitization of toothbrushes using: ultraviolet light sanitizer, domestic microwave oven, $0.2 \%$ chlorhexidine gluconate and to estimate the microbial contamination of toothbrushes when stored: inside the bathroom and outside the bathroom. It was found that Contamination is less in the brushes kept outside the bathroom as compared to brushes kept inside the bathroom. Possible reason can be bacteria present in the aerosol created from toilet flushing, reach brushes and contaminate them. These findings are similar to a study done by Elly et al[25] where they concluded that toothbrushes should be kept outside of bathrooms, so that they are out of aerosol range.

In our study it was also found that most effective method for sanitization of toothbrushes is microwave irradiation followed by UV rays and then chlorhexidine gluconate solution. These results were in accordance with a study done by Gujjari et al[26] where they found that microwave irradiation is an effective means of sterilization when compared to UV radiation as in microwave irradiation thermal effect on cellular content of microorganisms results in rupture of cell membrane and leakage of nucleic acid \& protein from cells leading to cell death or cell lysis. Chibebe et al[27] reported that exposure to microwave irradiation at $2450 \mathrm{MHz}$ results in bacterial inactivation.
However, UV radiation damages DNA and disrupts chemical bond between the atoms of DNA but longer exposure is required for the inactivation of microorganisms. Arrage et al[28] and Speert et al[29] concluded that longer exposure to UV light is necessary to ensure a complete inactivation of all microorganisms.

According to Rodrigues et al[30] simple and inexpensive act of spraying $0.12 \%$ chlorhexidine on toothbrush after each brushing helps in reducing bacterial load but the reduction was less when compared to microwave irradiation and UV radiation. A study conducted by Aysegul et al[31] highlighted the fact that although chlorhexidine solution is inexpensive, some bacteria get resistant to this chemical and the solution needs to be changed frequently because of which it is not so cost effective.

\section{Conclusion}

Proper storage and disinfection of the toothbrush is as important as brushing your teeth for a healthy and germ free life. Toothbrushes can serve as a means of direct transmission of microorganisms or it can act as a source of reintroduction of microorganisms from infected to non-infected tissues. Toothbrush has to be considered as an important source of pathogens in this era of organ transplants and changes in immune system. The traumatization of the people with their toothbrush can become a root for entry of microorganisms. Therefore, more studies of microorganisms on used brushes, the total number and the type of organisms involved are required to be done. Studies should include both toothbrushes from infected and healthy mouths. The effect of short- and long-term use of various oral rinses and toothpastes should be examined. While, maintaining the hygiene of the oral cavity not only toothbrushing should be considered but oral hygiene devices should also be kept clean.

Financial Disclosure: Nil.

Conflict of Interest: None declared.

\section{References}

1. McCarthy C, Snyder ML, Parker RB. The indigenous flora of man. I - The newborn to the 1 year old infant. Arch Oral Biol 1965;10:61-70 doi:10.1016/0003-9969(65)90058-0

2. Socransky SS, Manganiello SD. The oral microbiota of man from birth to senility. J Periodontol 1971;42(8):485-496 doi:10.1902/ jop.1971.42.8.485

3. MacFarlane TW, Samaranayake LP. Oral ecosystem and dental plaque. In: Clinical Oral Microbiology. Editor: Sayer L. London: Wright, 1989., pp 21-31 
4. Catalanotto FA, Shklair IL, Keene HJ. Prevalence and localization of Streptococcus mutans in infants and children. J Am Dent Assoc 1975;91(3):606-609 doi:10.14219/jada.archive.1975.0398

5. Fujiwara T, Sasada E, Mima N, Ooshima T. Caries prevalence and salivary mutans streptococci in 0-2-year-old children of Japan. Community Dent Oral Epidemiol 1991;19(3):151-154 doi:10.1111/j.1600-0528.1991.tb00131.x

6. Li Y, Caufield PW. The fidelity of initial acquisition of mutans streptococci by infants from their mothers. J Dent Res 1995;74(2):681-685 doi:10.1177/00220345950740020901

7. Newbrun E. Preventing dental caries: breaking the chain of transmission. J Am Dent Assoc 1992;123(6):55-59 doi:10.14219/jada. archive.1992.0183

8. Azevedo RVP. O emprego da bacteriocinotipagem (mutacinotipagem), no rastreamento epidemiológico de estreptococos do grupo mutans. Biomedical Science Institute of the University of São Paulo. Ph.D. Thesis, São Paulo, Brazil 1988, pp 110.

9. Köhler B, Bratthall D. Intrafamilial levels of Streptococcus mutans and some aspects of the bacterial transmission. Scand J Dent Res 1978;86(1):35-42 doi:10.1111/j.1600-0722.1978.tb00605.x

10. Svanberg M. Contamination of toothpaste and toothbrush by Streptococcus mutans. Scand J Dent Res 1978;86(5):412-414 doi:10.1111/j.1600-0722.1978.tb00646.x

11. Grewal N, Swaranjit K. A study of toothbrush contamination at different time intervals and comparative effectiveness of various disinfecting solutions in reducing toothbrush contamination. J Indian Soc Pedod Prev Dent 1996;14(1):10-13

12. Glass RT, Lare MM. Toothbrush contamination: a potential health risk?. Quintessence Int 1986;17(1):39-42

13. Gujjari SK, Gujjari AK, Patel PV, Shubhashini PV. Comparative evaluation of ultraviolet and microwave sanitization techniques for toothbrush decontamination. J Int Soc Prev Community Dent 2011;1(1):20-26 doi:10.4103/2231-0762.86383

14. Chandrdas D, Jayakumar HL, Chandra M, Katodia L, Sreedevi A. Evaluation of antimicrobial efficacy of garlic, tea tree oil, cetylpyridinium chloride, chlorhexidine, and ultraviolet sanitizing device in the decontamination of toothbrush. Indian J Dent 2014;5(4):183-189 doi:10.4103/0975-962X.144718

15. Sconyers JR, Crawford JJ, Moriarty JD. Relationship of bacteremia to toothbrushing in patients with periodontitis. J Am Dent Assoc 1973;87(3):616-622 doi:10.14219/jada.archive.1973.0453

16. Silver JG, Martin AW, McBride BC. Experimental transient bacteraemias in human subjects with varying degrees of plaque accumulation and gingival inflammation. J Clin Periodontol 1977;4(2):92-99 doi:10.1111/j.1600-051x.1977.tb01888.x
17. Kozai K, Iwai T, Miura K. Residual contamination of toothbrushes by microorganisms. ASDC J Dent Child 1989;56(3):201-204

18. Dayoub MB, Rusilko D, Gross A. Microbial contamination of toothbrushes. J Dent Res 1977;56(6):706 doi:10.1177/002203457 70560063501

19. Meier S, Collier C, Scaletta MG, Stephens J, Kimbrough R, Kettering JD. An in vitro investigation of the efficacy of CPC for use in toothbrush decontamination. J Dent Hyg 1996;70(4):161165

20. Malmberg E, Birkhed D, Norvenius G, Norén JG, Dahlén G. Microorganisms on toothbrushes at day-care centers. Acta Odontol Scand 1994;52(2):93-98 doi:10.3109/00016359409029061

21. Cesco RT, Bignelli P, Santos CP, Ito IY. Toothbrushes: evaluation of contamination level by streptococci of mutans group. 5th World Congress on Preventive Dentistry. Transamérica Hotel, São Paulo, Brazil 1995, April 27 - 30, pp 103.

22. Denny FW. Risk of toothbrushes in the transmission of respiratory infections. Pediatr Infect Dis J 1991;10(9):710-711

23. Caudry SD, Klitorinos A, Chan EC. Contaminated toothbrushes and their disinfection. J Can Dent Assoc 1995;61(6):511-516

24. Glass RT, Jensen HG. More on the contaminated toothbrush: the viral story. Quintessence Int 1988;19(10):713-716

25. Montero EA, Isom IB, Fults J, Cvijanovich S, Chismark A, Tran BB. The Effects of proximity on aerosol distribution of bacteria on toothbrushes. CDHA Journal 2012;27(2):17-21

26. Gujjari SK, Gujjari AK, Patel PV, Shubhashini PV. Comparative evaluation of ultraviolet and microwave sanitization techniques for toothbrush decontamination. J Int Soc Prev Community Dent 2011;1(1):20-26 doi:10.4103/2231-0762.86383

27. Chibebe J Jr, Pallos D. Evaluation of sterilization of toothbrushes in a microwave oven (in vitro study). Rev Biociênc 2001;7:39-42

28. Arrage AA, Phelps TJ, Benoit RE, White DC. Survival of subsurface microorganisms exposed to UV radiation and hydrogen peroxide. Appl Environ Microbiol 1993;59(11):3545-3550 doi:10.1128/aem.59.11.3545-3550.1993

29. Speert DP, Wannamaker LW. Susceptibility of group A streptococci to oleic acid and ultraviolet light. Comparison of strains from throat and skin. J Lab Clin Med 1980;96(2):252-257

30. Rodrigues LK, Motter CW, Pegoraro DA, Menoli APV, Menolli RA. Microbiological contamination of toothbrushes and identification of a decontamination protocol using chlorhexidine spray. Revista Odonto Ciência 2012;27(3):213-217

31. Ayşegül O, Elgin IE, Gulcin A, Nedim S. The efficacy of chlorhexidine spray vs mouthwash in the microbial contamination of child toothbrushes. J Dent Child (Chic) 2007;74(3):177-181 